\title{
Pengaruh project-based learning berbantuan instagram terhadap literasi lingkungan dan hasil belajar kognitif
}

\author{
Sintya Yuliandini, Hadi Suwono*, Sueb \\ Universitas Negeri Malang, Jl. Semarang No. 5 Malang, Jawa Timur, Indonesia \\ *Penulis korespondensi, Surel: hadi, suwono@yahoo.com
}

Paper received: 02-01-2021; revised: 15-01-2021; accepted: 30-01-2021

\begin{abstract}
The objectives of the research are: 1) to know the difference of students environment literacy which get Project-Based Leaming (PjBL) assisted instagram and Project-Based Learning (PJBL), 2) to know the difference of cognitive Ic result of students who get Project-Based Learning (PjBL) assisted instagram and Project-Based Learning (PBL). This research uses mixed methods with embedded design, Data were collected guantitatively through pretest and postest, then analyzed by normality test, homogeneity test, hypothesis anakova test, and eflect size calculation. In addition, data. Were collected gualittively through discussions in instagram, guestionnaires, and interviews which were further analyzed by Miles and Huberman model. The results of the research are: 1) there are differences in environmental lteracy of students who received PJBL assisted instagram and PjBL with covariate (pretest) has no effect on environmental and student literacy, and 2) there are difference of cognitive Icarning outcomes of students who received PJBL assisted instagram and PJBL with covariate (pretest) Has no effect on students cognitive Icarning outcomes.
\end{abstract}

Keywords: environmental literacy; cogntive Icarning outcomes; ecology; environmental change and conservation; project-based learning; instagram

\begin{abstract}
Abstrak
Tujuan penelitan yaitu: 1) mengetahui perbedaan literasi lingkungan siswa yang mendapatkan Project-Based Learning (PIBL) berbantuan instagram dan Project-Based Learning (PJBL), 2) mengetahui perbedaan hasil belajar kognitif siswa yang mendapatkan Project-Based Learning (PBL) berbantuan instagram dan Project-Based Learning (PiBL). Penelitian ini menggunakan mixed methods dengan embedded design. Data dikumpulkan secara kuantitafif melalui pretes dan postes, kemudian dianalisis dengan uji normalitas, uji homogenitas, uji hipotesis anakova, dan penghitungan efect size. Selain itu, data dikumpulkan secara kualitatif melalui diskusi di instagram, angket, dan wawancara yang selanjutnya dianalisis dengan model Miles and Huberman. Hasil penelitian yaitu: 1) ada lingkungan siswa yang mendapatkan PjBL berbantuan instagram dan PIBL dengan kovariat (pretes) tidak berpengaruh terhadap literasi lingkungan dan siswa, an 2) ada perbedaan hasil belajar kognitif siswa yang mendapatkan PJBL berbantuan instagram dan PjBL dengan kovariat (pretes) tidak berpengaruh hasil belajar kognitif siswa
\end{abstract}

Kata kunci: literasi lingkungan, hasil belajar kognitif; ekologi; lingkungan perubahan dan konservasi; pembelajaran berbasis proyek; instagram

\section{Pendahuluan}

Literasi lingkungan adalah kemampuan untuk membaca dan menulis tentang lingkungan, dan mengembangkan masyarakat yang dapat membuat keputusan dan pilihan untuk mempertahankan lingkungannya (Varisli, 2009). Beberapa komponen literasi lingkungan berfokus pada pengetahuan (knowledge), keterampilan (skills), serta sikap dan perilaku (affective) yang berkaitan dengan literasi lingkungan (Camier, 2009: Hollweg dkk, 20113 Kostova \& Vladimirova 2010: MeBeth \& Volt, Roth 1992). Literasi lingkungan 
bertujuan untuk memberi pengetahuan lingkungan kepada masyarakat dalam memanfaatkan sumberdaya alam yang ada agar menghindari kerusakan lingkungan.

Salah satu contoh kerusakan lingkungan yaitu berkurangnya sumber mata air. Terkait masifnya pembangunan berbasis pariwisata di Kota Batu, Walhi Jawa Timur menyebutkan sekitar 50 persen atau separuh Kota Batu telah mengalami kerusakan lingkungan. Dari 11.227 hektar luasan hutan, 5.900 hektar telah rusak. Dari 111 sumber mata air yang tercatat, kini tinggal 57 yang bisa saja terus berkurang bila tidak ada perlindungan dan pelestarian (Riski, 2016). Hal negatif yang muncul dalam lingkungan manusia disebabkan oleh tingkah laku dan tindakan manusia sendiri, seperti gaya hidup orang berada yang kurang serasi, adanya pemborosan dalam penggunaan SDA, kebodohan, dan kemelaratan menyebabkan pencemaran dan kerusakan lingkungan sehingga mengganggu stabilitas ekosistem (Supardi, 1994). Meskipun alasan masalah lingkungan adalah manusia, solusi untuk masalah ini juga manusia.

Dalam UU No. 32 tentang Perlindungan dan Pengelolaan Lingkungan Hidup (2009) pasal 65 poin keempat, disebutkan bahwa setiap orang berhak untuk berperan dalam perlindungan dan pengelolaan lingkungan sesuai dengan peraturan perundang-undangan. Hal ini berarti bahwa setiap individu harus memiliki tanggung jawab terhadap pengelolaan dan perlindungan lingkungannya khususnya para generasi muda. Salah satu cara untuk menanamkan sikap tanggung jawab dan kepedulian lingkungan yang baik pada generasi muda yaitu melalui pendidikan lingkungan. Pendidikan lingkungan merupakan usaha untuk melestarikan lingkungan yang dilakukan dari generasi ke generasi yang akan datang (Sumarmi, 2008). Dalam belajar mengenai lingkungan diperlukan pemahaman konsep pada siswa. Pemahaman konsep ini dapat dilihat dari hasil belajar siswa.

Berdasarkan pengisian wawancara tertulis oleh siswa kelas X MIPA 1, 2, dan 3 SMA Negeri 1 Batu pada bulan Oktober 2016, dari 90 responden, sebanyak 70\% responden $(63$ responden) kurang puas dengan hasil belajar biologi mereka. Hal ini dikarenakan nilai yang mereka dapat masih kurang memuaskan dan perlu ditingkatkan lagi. Data ini didukung dari hasil nilai rapor semester 1 yang menunjukkan nilai rerata siswa masih sesuai KKM atau hanya sedikit diatas KKM yaitu antara 70 hingga 75 . Untuk meningkatkan hasil belajar pada ranah kognitif tersebut, diperlukan model pembelajaran yang menunjang, salah satunya yaitu model pembelajaran berbasis projek (Project-Based Learning).

Pembelajaran berbasis projek atau Project-Based Learning (PjBL) adalah pembelajaran yang didesain untuk persoalan yang kompleks sehingga siswa melakukan investigasi untuk memahaminya, menekankan pembelajaran dengan aktivitas yang lama, tugas yang diberikan pada siswa bersifat multidisiplin, ber-orientasi pada produk (Mahannal \& Wibowo, 2009). Agar pembelajaran ini terlaksana dengan baik, maka diperlukan alat bantu untuk menjadikan kegiatan belajar lebih mudah dan menyenangkan. Alat bantu yang dapat dimanfaatkan salah satunya yaitu media pembelajaran. Keberhasilan proses belajar membutuhkan media pembelajaran yang menarik dan tidak monoton. Salah satu media yang dapat digunakan berupa jejaring sosial instagram.

Berdasarkan pengisian angket siswa sebanyak 90 responden, sekitar $77,77 \%$ memiliki akun instagram, sedangkan 22,22\% tidak memiliki akun instagram. Penggunaan instagram lebih dimanfaatkan untuk mempermudah guru dalam memantau kegiatan siswa dan akan 
menjadi produk dari siswa nantinya. Oleh karena itu, penelitian dengan judul "Pengaruh Model Project Based Learning Berbantuan Instagram Terhadap Literasi Lingkungan dan Hasil Belajar Kognitif" dilakukan berdasarkan masalah yang ada pada kehidupan sehari-hari dengan harapan dapat meningkatkan kemampuan literasi lingkungan dan memberi motivasi siswa dalam hasil belajarnya serta mewujudkan visi dari SMA Negeri 1 Batu sebagai sekolah unggul berlandaskan iman dan takwa serta berbudaya lingkungan. Tujuan penelitian ini yaitu, (1) untuk mengetahui perbedaan literasi lingkungan siswa yang mendapatkan ProjectBased Learning berbantuan Instagram dan Project-Based Learning dengan menyesuaikan literasi lingkungan awal siswa, dan (2) untuk mengetahui perbedaan hasil belajar kognitif siswa yang mendapatkan Project-Based Learning berbanruan Instagram dan Project-Based Learning dengan menyesuaikan hasil belajar kognitif awal siswa.

\section{Metode}

Penelitian ini menggunakan mixed methods dengan embedded design. Penelitian ini dilaksanakan bulan Maret-April 2017 pada kelas X MIPA 1 dan X MIPA 4 SMA Negeri 1 Batu. Instrumen menggunakan soal tes literasi lingkungan yang juga digunakan untuk mengukur hasil belajar kognitif siswa dengan reliabilitas sebesar 0,769 (sangat tinggi). Analisis data yang digunakan terdiri atas analisis kuantitatif dan analisis kualitatif. Analisis data kuantitatif melalui uji statistika uji normalitas, uji homogenitas, uji hipotesis anakova, dan effect size. Sedangkan analisis data secara kualitatif dilakukan dengan menggunakan model Miles and Huberman.

\section{Hasil dan Pembahasan}

\subsection{HASIL}

\subsubsection{Analisis Kuantitatif Literasi Lingkungan dan Hasil Belajar Kognitif}

Data literasi lingkungan diperoleh secara kuantitatif dari nilai postes dan pretes yang telah diuji secara statistika. Pengujian dilakukan melalui rerata skor kelas, uji hipotesis anakova yang sebelumnya dilakukan uji normalitas dan homogenitas terlebih dahulu, dan penghitungan effect size.

\subsubsection{Rerata Skor Literasi Lingkungan}

Tabel 1. Rerata Skor Literasi Lingkungan

\begin{tabular}{llll}
\hline \multirow{2}{*}{ Perlakuan } & \multicolumn{2}{l}{ Skor Literasi Lingkungan } & Persentase \\
\cline { 2 - 3 } & Pretes & Postes & Peningkatan \\
\hline Kelas Kontrol (Project-Based Learning) & 59,00 & 79,91 & $20,9 \%$ \\
Kelas Eksperimen (Project-Based & 56,88 & 87,08 & $30,2 \%$ \\
Learning berbantuan Instagram) & & & \\
\hline
\end{tabular}

Rerata skor literasi lingkungan pada kelas kontrol yang menggunakan model ProjectBased Learning diperoleh dari skor pretes dan postes yaitu 59,00 dan 79,91. Skor literasi lingkungan pada kelas eksperimen yang menggunakan Project-Based Learning berbantuan Instagram diperoleh dari skor pretes dan postes yaitu 56,88 dan 87,00. Persentase peningkatan rerata skor yang diperoleh siswa di kelas eksperimen sebesar 30,2 \%. Berdasarkan data tersebut, peningkatan pada kelas eksperimen terlihat jauh lebih baik 
diban-dingkan dengan kelas kontrol yang mengalami peningkatan rerata skor literasi lingkungan sebesar $20,91 \%$.

\subsubsection{Uji Hipotesis Literasi Lingkungan}

Setelah dilakukan uji normalitas dan uji homogentitas data, maka selanjutnya yaitu uji hipotesis menggunakan analisis statistika anakova.

Tabel 2. Hasil Uji Statistik Anakova Model Pembelajaran terhadap Literasi Lingkungan

\begin{tabular}{llllll}
\hline Source & $\begin{array}{l}\text { Type III Sum of } \\
\text { Squares }\end{array}$ & Df & Mean Square & F & Sig. \\
\hline PRELITLING & 146.069 & 1 & 146.069 & 1.702 & .197 \\
MODEL & 964.075 & 1 & 964.075 & 11.235 & .001 \\
\hline
\end{tabular}

$F_{\text {hitung }}$ model pembelajaran sebesar 11,235 dengan nilai $\mathrm{p}$ 0,001. Nilai $\mathrm{p}$ ini jauh lebih kecil dari $\alpha(0,05)$ yang digunakan untuk pengujian. Dengan demikian Ho ditolak dan Ha diterima yang menyatakan bahwa ada perbedaan literasi lingkungan antara kelas yang menerapkan Project-Based Learning berbantuan Instagram dan Project-Based Learning. Kovariat yang berupa pretes literasi lingkungan tidak berpengaruh terhadap literasi lingkungan dengan $\mathrm{p}=0,197>\alpha(=0,05)$.

\subsubsection{Penghitungan Effect Size Literasi Lingkungan}

Tabel 3. Penghitungan Effect Size Litreasi Lingkungan

\begin{tabular}{ll}
\hline Kelas & Skor Cohen's d \\
\hline X MIPA 1 (Eksperimen) & 3,04 \\
X MIPA 4 (Kontrol) & 2,62 \\
\hline
\end{tabular}

Penghitungan effect size yang telah dilakukan didapatkan skor sebesar 3,04 untuk kelas eksperimen dan 2,62 untuk kelas kontrol. Hal ini dapat diartikan bahwa perlakuan ProjectBased Learning dan Project-Based Learning berbantuan instagram secara signifikan memberikan pengaruh yang sangat besar terhadap peningkatan literasi lingkungan siswa.

\subsubsection{Analisis Kualitatif Literasi Lingkungan}

Data hasil penelitian yang dapat dianalisis secara kualitatif yaitu diskusi (tanya jawab) selama pembelajaran pada jejaring sosial instagram dan hasil dokumentasi kegiatan di sekolah. Berdasarkan hasil diskusi pada jejaring sosial instagram dari tiga tugas yang diunggah di akun instagram, siswa sudah menunjukkan tiga komponen literasi lingkungan yang meliputi komponen pengetahuan (ekologycal knowledge, sosio-political knowledge, environmental issue), keterampilan/kognitif skill (identifikasi isu dan analisis isu), serta perilaku (environmental responsible behavior). Ketiga tugas projek yang diunggah meliputi artefak hasil kegiatan identifikasi komponen ekosistem, identifikasi perilaku masyarakat terhadap sampah, dan pembuatan produk daur ulang limbah. 


\subsubsection{Rerata Skor Hasil Belajar Kognitif}

Tabel 4. Rerata Skor Hasil Belajar Kognitif

\begin{tabular}{|c|c|c|c|}
\hline \multirow[t]{2}{*}{ Perlakuan } & \multicolumn{2}{|c|}{ Skor Hasil Belajar Kognitif } & \multirow{2}{*}{$\begin{array}{l}\text { Persentase } \\
\text { Peningkatan }\end{array}$} \\
\hline & Pretes & Postes & \\
\hline Kelas Kontrol (Project-Based Learning) & 59,00 & 79,91 & $20,9 \%$ \\
\hline $\begin{array}{l}\text { Kelas Eksperimen (Project-Based } \\
\text { Learning berbantuan Instagram) }\end{array}$ & 56,88 & 87,08 & $30,2 \%$ \\
\hline
\end{tabular}

Rerata skor hasil belajar kognitif pada kelas kontrol yang menggunakan model ProjectBased Learning diperoleh dari skor pretes dan postes yaitu 59,00 dan 79,91. Skor hasil belajar kognitif pada kelas eksperimen yang menggunakan Project-Based Learning berbantuan Instagram diperoleh dari skor pretes dan postes yaitu 56,88 dan 87,00. Persentase peningkatan rerata skor yang diperoleh siswa di kelas eksperimen sebesar 30,2 \%. Berdasarkan data tersebut, peningkatan pada kelas eksperimen terlihat jauh lebih baik dibandingkan dengan kelas kontrol yang mengalami peningkatan rerata skor hasil belajar kognitif sebesar 20,91\%.

\subsubsection{Uji Hipotesis Hasil Belajar Kognitif}

Setelah dilakukan uji normalitas dan uji homogentitas data, maka selanjutnya yaitu uji hipotesis menggunakan analisis statistika anakova.

Tabel 5. Hasil Uji Statistik Anakova Model Pembelajaran terhadap Hasil Belajar Kognitif

\begin{tabular}{llllll}
\hline Source & $\begin{array}{l}\text { Type III Sum of } \\
\text { Squares }\end{array}$ & Df & Mean Square & F & Sig. \\
\hline PRELITLING & 146.069 & 1 & 146.069 & 1.702 & .197 \\
MODEL & 964.075 & 1 & 964.075 & 11.235 & .001 \\
\hline
\end{tabular}

$F_{\text {hitung }}$ model pembelajaran sebesar 11,235 dengan nilai p 0,001. Nilai p ini jauh lebih kecil dari $\alpha(0,05)$ yang digunakan untuk pengujian. Dengan demikian Ho ditolak dan Ha diterima yang menyatakan bahwa ada perbedaan hasil belajar kognitif antara kelas yang menerapkan Project-Based Learning berbantuan Instagram dan Project-Based Learning. Kovariat yang berupa pretes hasil belajar kognitif tidak berpengaruh terhadap hasil belajar kognitif dengan $p=0,197>\alpha(=0,05)$.

\subsubsection{Penghitungan Effect Size Literasi Lingkungan}

Tabel 6. Penghitungan Effect Size Litreasi Lingkungan

\begin{tabular}{ll}
\hline Kelas & Skor Cohen's d \\
\hline X MIPA 1 (Eksperimen) & 3,04 \\
X MIPA 4 (Kontrol) & 2,62 \\
\hline
\end{tabular}

Penghitungan effect size yang telah dilakukan didapatkan skor sebesar 3,04 untuk kelas eksperimen dan 2,62 untuk kelas kontrol. Hal ini dapat diartikan bahwa perlakuan ProjectBased Learning dan Project-Based Learning berbantuan instagram secara signifikan memberikan pengaruh yang sangat besar terhadap peningkatan hasil belajar kognitif siswa. 


\subsubsection{Analisis Kualitatif Hasil Belajar Kognitif}

Data hasil penelitian yang dapat dianalisis secara kualitatif yaitu diskusi (tanya jawab) selama pembelajaran pada jejaring sosial instagram dan hasil dokumentasi kegiatan di sekolah. Berdasarkan hasil diskusi pada jejaring sosial instagram dari tiga tugas yang diunggah di akun instagram yaitu meliputi artefak hasil kegiatan identifikasi komponen ekosistem, identifikasi perilaku masyarakat terhadap sampah, dan pembuatan produk daur ulang limbah. siswa telah menunjukkan kemampuan kognitif dimulai dari tingkatan C1 (mengingat), C2 (memahami), C3 (Menerapkan), C4 (menganalisis), C5 (menilai), dan C6 (mencipta).

Berdasarkan hasil angket motivasi belajar siswa hampir seluruhnya (63,05\%) siswa setuju dengan penerapan Project-Based Learning berbantuan Instagram. Namun, juga masih ada siswa yang tidak setuju dengan penerapan Project-Based Learning berbantuan Instagram. Selanjutnya yaitu hasil wawancara yang dilakukan pada 15 siswa yang terdiri dari 5 siswa yang memperoleh nilai tertinggi, 5 siswa yang memperoleh nilai menengah, dan 5 siswa yang memiliki nilai terendah berdasarkan hasil postes. Wawancara ini bertujuan untuk mendapatkan informasi tentang pembe-lajaran yang telah mereka dapatkan. Berdasarkan wawancara dari 15 siswa, 9 siswa setuju belajar dengan menggunakan Project-Based Learning berbantuan instagram, sedangkan sisanya tidak setuju. Siswa yang setuju beralasan bahwa pembelajaran menggunakan Project-Based Learning berbantuan instagram merupakan sesuatu yang berbeda, lebih mudah untuk pengumpulan tugas, dan masyarakat luas dapat melihat pembelajaran yang diperoleh siswa karena banyak yang sudah menggunakan instagram. Sedangkan siswa yang tidak setuju karena tidak semua siswa menggunakan instagram, sehingga kurang optimal dalam belajar.

Berdasarkan hasil refleksi pembelajaran, pendapat dari siswa bahwa mereka merasakan Project-Based Learning berbantuan Instagram dapat meningkatkan literasi lingkungan dan hasil belajar kognitif. Setelah mengalami Project-Based Learning berbantuan instagram, mereka lebih menghargai sesama teman. Selain itu, siswa lebih peka terhadap lingkungan dengan cara menjaga kebersihan dan mengunggah hasil belajarnya pada akun instagram agar masyarakat luas merasakan manfaat pembelajaran yang siswa peroleh.

\subsection{Pembahasan}

\subsubsection{Perbedaan Literasi Lingkungan antara Siswa yang Dibelajarkan dengan menggunakan PjBL berbantuan Instagram dan yang Dibelajarkan dengan Menggunakan PjBL}

Hasil analisis data memperlihatkan bahwa ada perbedaan literasi ling-kungan antara siswa yang dibelajarkan dengan menggunakan Project-Based Learning berbantuan Instagram dan siswa yang dibelajarkan dengan mengguna-kan Project-Based Learning. Hal ini ditunjukkan dari nilai p uji anakova yaitu 0,001<0,05. Dari hasil analisis tersebut dapat dikatakan bahwa Project-Based Learning berbantuan Instagram berpengaruh terhadap literasi lingkungan siswa sehingga menyebabkan literasi siswa pada kelas eksperimen lebih baik daripada kelas kontrol.

Dilihat dari persentase peningkatan nilai pretes dan postes, terjadi peningkatan nilai literasi lingkungan pada kedua kelas. Pada kelas eksperimen menunjukkan adanya 
peningkatan yang lebih besar. Presentase peningkatan rerata nilai yang diperoleh siswa di kelas eksperimen sebesar 30,2 \%. Sedangkan peningkatan pada kelas kontrol sebesar 20,91\%. Adanya peningkatan literasi lingkungan pada kelas kontrol menunjukkan bahwa pembelajaran menggunakan Project-Based Learning dapat meningkatkan literasi lingkungan siswa, tetapi dengan pembelajaran Project-Based Learning berbantuan Instagram dapat lebih meningkatkan literasi lingkungan siswa pada kelas ekperimen. Dalam melaksanakan sintaks Project-Based Learning dibantu dengan media Instagram agar pelaksanaan sintaks lebih terkontrol.

Dengan adanya media pembelajaran berupa jejaring sosial Instagram guru akan lebih efektif dalam menilai kerja siswa secara langsung serta siswa juga mudah untuk berkomunikasi dengan siswa lainnya dan guru saat mengerjakan projek di luar jam pelajaran. Siswa juga dapat berdiskusi secara terbuka bersama siswa lain dan guru dalam kolom komentar foto/video yang diunggah oleh siswa lainnya. Hal ini didukung oleh penelitian Klostova \& Vladimirova (2010) yang menunjukkan bahwa pengenalan pembelajaran berbasis projek dan dibantu komputer menciptakan kemungkinan yang baik untuk belajar berinteraksi, menyimpan data dan mengoreksi bahan yang diproduksi dalam format yang jelas dan mudah diakses oleh pengguna lain.

Berdasarkan hasil angket motivasi belajar siswa yang diberikan kepada siswa kelas X MIPA 1 (kelas eksperimen), sebanyak 63\% siswa tertarik menggunakan media sosisal instagram dalam pembelajaran yang dilakukan guru. Hal ini juga didukung dari wawancara kepada 15 siswa yang memiliki peringkat teratas, menengah, dan terbawah berdasarkan hasil belajar kognitif yang menunjukkan bahwa 9 siswa tertarik dengan penggunaan media pembelajaran instagram dalam pembelajaran dengan berbagai alasan, yaitu mempermudah siswa dalam pengum-pulan tugas, memberikan suasana baru dalam belajar sehingga tidak akan bosan, serta dengan adanya instagram mereka dapat berbagi informasi dengan masyarakat luas, karena sekarang ini banyak masyarakat yang sudah banyak menggunakan instagram. Dari sini terlihat jelas bahwa gaya belajar siswa sekarang telah berubah. Mereka cenderung lebih senang belajar dengan sesuatu yang sering mereka gunakan berkomunikasi setiap hari, seperti jejaring sosial instagram. Hal ini didukung penelitian dari Blair \& Serafini (2014) yang menyatakan bahwa jejaring sosial dapat mengevaluasi kelas berbasis teknologi yang terus berkembang, serta suatu pergeseran paradigma gaya belajar yang diarahkan ke siswa.

Berdasarkan analisis data kualitatif melalui dokumentasi diskusi pada instagram, kebanyakan siswa bisa memberi alasan jawaban yang tepat dan beberapa siswa juga bisa memunculkan masalah baru yang harus dijawab oleh siswa lainnya yang terkait dengan hasil kerja projek yang mereka lakukan. Projek pertama membahas tentang identifikasi komponen dan interaksi anatarkomponen ekosistem, projek kedua tentang identifikasi perilaku masyarakat terhadap lingkungan, dan projek ketiga pembuatan produk daur ulang limbah. Dari hasil tanya jawab tersebut memperlihatkan bahwa siswa telah mampu berliterasi lingkungan dengan baik. Hal ini didukung oleh (Bodzin $d k k$., 2010; Roth, 1992) yang menyatakan bahwa seseorang yang berliterasi lingkungan mampu mengidentifikasi, menyelidiki, dan merumuskan solusi potensial untuk masalah lingkungan, serta memiliki pengetahuan dan pemahaman bagaimana sistem alam bekerja dan dampak yang ditimbulkan. 
Dari hasil analisis pada penelitian ini, literasi lingkungan kelas kontrol dan kelas eksperimen keduanya mengalami peningkatan, tetapi pada kelas eksperimen memiliki persentase peningkatan yang lebih besar dibanding kelas kontrol. Hal ini membuktikan bahwa pembelajaran dengan menggunakan Project-Based Learning berbantuan Instagram lebih berpotensi untuk meningkatkan literasi lingkungan siswa daripada pembelajaran dengan menggunakan Project-Based Learning saja. Penelitian ini sejalan dengan penelitian terdahulu yang dilakukan oleh Utami $d k k$. (2015) mengungkap bahwa ada pengaruh model pembelajaran PjBL berbantu Instagram terhadap kemampuan berpikir kreatif siswa.

\subsubsection{Perbedaan Hasil Belajar Kognitif antara Siswa yang Dibelajarkan dengan Menggunakan PjBL berbantuan Instagram dan yang Dibelajarkan dengan Menggunakan PjBL}

Hasil analisis data nilai belajar kognitif siswa pada kelas kontrol yang menggunakan model Project-Based Learning dan kelas eksperimen Project-Based Learning berbantuan Instagram diperoleh dari skor pretes dan postes literasi lingkungan. Hasil analisis data memperlihatkan bahwa ada perbedaan hasil belajar kognitif antara siswa yang dibelajarkan dengan menggunakan Project-Based Learning berbantuan Instagram dan siswa yang dibelajarkan dengan menggunakan Project-Based Learning. Hal ini ditunjukkan dari nilai p uji anakova yaitu 0,001 < 0,05. Dari hasil analisis tersebut dapat dikatakan bahwa Project-Based Learning berbantuan Instagram berpengaruh terhadap hasil belajar kognitif siswa sehingga menyebabkan hasil belajar kognitif pada kelas eksperimen lebih baik daripada kelas kontrol.

Peningkatan hasil belajar kognitif terlihat dari peningkatan rerata skor hasil belajar sebelum perlakuan (pretes) dan rerata skor hasil belajar setelah perlakuan (postes). Berdasarkan rerata nilai belajar kognitif siswa pada kelas kontrol yang menggunakan model Project-Based Learning diperoleh dari skor pretes sebesar 59 dan postes sebesar 79,91. Nilai hasil belajar kognitif siswa pada kelas eksperimen yang menggunakan Project-Based Learning berbantuan Instagram diperoleh dari skor pretes sebesar 56,88 dan skor postes sebesar 87. Persentase peningkatan rerata nilai yang diperoleh siswa di kelas eksperimen sebesar 30,2\%. Berdasarkan data tersebut, peningkatan pada kelas eksperimen terlihat jauh lebih baik dibandingkan dengan kelas kontrol yang mengalami peningkatan rerata nilai literasi lingkungan sebesar 20,91\%. Peningkatan rerata nilai literasi lingkungan tersebut juga menandakan bahwa terjadi peningkatan hasil belajar kognitif siswa. Hal ini didukung pendapat Chaffee (1999) yang mengemukakan bahwa berbagai media massa (sekarang lebih dikenal dengan jejaring sosial) dapat memberikan efek kognitif sebagai akibat yang timbul pada diri komunikan yang sifatnya informatif bagi dirinya. Dalam efek kognitif ini membahas tentang bagaimana media massa dapat membantu khalayak dalam mempelajari informasi yang bermanfaat dan menampilkan keterampilan kognitifnya. Hal ini sejalan dengan hasil penelitian Mujib (2013) yang melaporkan bahwa penggunaan internet sebagai media belajar dapat meningkatkan hasil belajar siswa.

Adanya peningkatan hasil belajar kognitif pada kelas kontrol menunjukkan bahwa pembelajaran menggunakan Project-Based Learning dapat meningkatkan hasil belajar kognitif siswa, tetapi dengan pembelajaran Project-Based Learning berbantuan Instagram dapat lebih meningkatkan hasil belajar kognitif siswa pada kelas eksperimen. Hal ini dikarenakan jejaring sosial instagram merupakan suatu media pembelajaran yang digunakan untuk mempermudah guru berkomunikasi dengan siswa diluar jam pelajaran, sehingga 
waktu tidak terbatas hanya di sekolah saja. Dengan adanya media pembelajaran berupa jejaring sosial instagram, siswa juga tidak perlu membuat hardfile laporan kegiatan projek, mereka dapat langsung mengunggahnya di akun jejaring sosial instagram dengan diberi keterangan yang ringkas dan jelas. Sesuai dengan pendapat Kemp dan Dayton (1985) dalam Falahudin (2014) yang menyatakan bahwa manfaat media pembelajaran yaitu proses pembelajaran menjadi lebih jelas dan menarik, proses pembelajaran menjadi lebih interaktif, efisiensi dalam waktu dan tenaga. meningkatkan kualitas hasil pembelajaran, proses pembelajaran dapat dilakukan dimana saja dan kapan saja, menjadikan materi yang abstrak menjadi lebih konkrit, mengatasi kendala keterbatasan ruang dan waktu.

Berdasarkan wawancara dengan 10 siswa di kelas kontrol yang menggu-nakan Project-Based Learning, kelemahan PjBL yaitu menyita banyak biaya dan waktu, serta pembuatan produk berupa hardfile laporan kegiatan projek yang membuat mereka bosan. Kendala waktu dan biaya memang menjadi kelemahan Project-Based Learning, seperti yang dikemukakan oleh Wena (2014) bahwa kelemahan Project-Based Learning yaitu memerlukan banyak waktu yang harus diselesaikan untuk menyelesaikan masalah, memerlukan biaya yang cukup banyak, serta banyak peralatan yang cukup banyak. Oleh karena itu, dengan adanya jejaring sosial instagram menjadi salah satu alternatif untuk menghemat penggunaan waktu dan biaya yang cukup banyak dalam pembelajaran menggunakan Project-Based Learning.

\section{Simpulan}

\subsection{Simpulan}

Berdasarkan hasil penelitian dan pembahasan yang diuraikan, dapat ditarik simpulan sebagai berikut. (1) Ada perbedaan literasi lingkungan siswa yang mendapatkan ProjectBased Learning berbantuan instagram dan Project-Based Learning dengan kovariat (pretes) tidak berpengaruh terhadap literasi lingkungan. Selanjutnya diperkuat dengan hasil nilai effect size sebesar 3,04 untuk kelas eksperimen dan 2,62 untuk kelas kontrol yang menyatakan bahwa perlakuan Project-Based Learning berbantuan instagram dan ProjectBased Learning secara signifikan memberikan pengaruh yang sangat besar terhadap peningkatan literasi lingkungan siswa. Kesimpulan ini didukung pula oleh analisis kualitatif dari hasil diskusi pada instagram, angket, dan wawancara. (2) Ada perbedaan hasil belajar kognitif siswa yang mendapatkan Project-Based Learning berbantuan instagram dan ProjectBased Learning dengan kovariat (pretes) tidak berpengaruh terhadap hasil belajar kognitif siswa. Selanjutnya diperkuat dengan hasil nilai effect size sebesar 3,04 untuk kelas eksperimen dan 2,62 untuk kelas kontrol yang menyatakan bahwa perlakuan Project-Based Learning berbantuan instagram dan Project-Based Learning secara signifikan memberikan pengaruh yang sangat besar terhadap peningkatan hasil belajar kognitif siswa. Kesimpulan ini didukung pula oleh analisis kualitatif dari hasil diskusi pada instagram, angket, dan wawancara.

\subsection{Saran}

Berdasarkan hasil penelitian dapat diberikan saran sebagai berikut. (1) Bagi guru, model Project-Based Learning berbantuan instagram ini dapat diterapkan pada materi dan konsep yang lain, karena terbukti dapat mening-katkan literasi lingkungan dan hasil belajar 
kognitif siswa. Dengan menerapkan Project-Based Learning berbantuan instagram, maka akan menambah model pembelajaran lain yang lebih menyenangkan sesuai dengan gaya belajar siswa.

Bagi peneliti lain, model Project-Based Learning berbantuan instagram ini dapat diteliti pada materi dan konsep yang lain dengan perbaikan instrumen yang terkait dengan bahasa yang komunikatif sehingga mudah dipahami oleh siswa. Selain itu, penggunaan instagram lebih ditekankan dan dikendalikan lagi supaya siswa termotivasi dan dapat melaksanakan pembelajaran dengan optimal.

\section{Daftar Rujukan}

Blair, R., \& Serafini, M,T. (2014). Integration of Education: Using Social Media Networks to Engage Students. http://www.iiis.org/CDs2014/CD2014SCI/ IMSCI_2014/PapersPdf/HA312LG.pdf (online) diakses pada 20 November 2016.

Blumefeld, C, P., Soloway, E., Marx, W, R., Krajcik, S,J., Guzdial, M., \& Palincsar, A. (2011). Motivating ProjectBased Learning: Sustaining the Doing, Supporting the Learning. Journal Educational Psychologist. Vol.26.

Bodzin, M, A., Klein, S, B., \& Weaver, S. (2010). The Inclution of Environmental Education in Science Teacher Education. USA: Springer.

Carrier, S.J. (2009). Environmental Education in the Schoolyard: Learning Styles and Gender. J. Environmental Education 40(3), 2-12.

Chaffee, H,S. (1999). Communication Studies » Communication Reception and Effects. United States of America: Wolfgang Donsbach.

Falahudin, I. (2014). Pemanfaatan Media Dalam Pembelajaran. Jurnal Lingkar Widyaiswara. Vol 1. Nomor 4. 104-117.

Hollweg, K. S., Taylor, J. R., Bybee, R. W., Marcinkowski, T. J., McBeth, W. C., \& Zoido, P. (2011). Developing a framework for assessing environmental literacy. Washington, DC: North American Association for Environmental Education.

Kostova, Z \& Vladimirova, E. (2010). Development Of Environmental Literacy by Interactive Didactic Strategies. Chemistry. 19(3), 50-70.

Mahanal, S. \& Wibowo, A.L. (2009). Penerapan Pembelajaran Lingkungan Hidup Berbasis Proyek untuk Memberdayakan Kemampuan Berpikir Kritis, Penguasaan Konsep, dan Sikap Siswa (Studi di SMAN 9 Malang). Makalah Disajikan dalam Seminar Nasional Pendidikan Lingkungan Hidup dan Interkonferensi BKPSL. Universitas Negeri Malang. 20-21 Juni 2009-07-15.

McBeth, W., \& Volk, L, T. (2010). The National Environmental Literacy Project: A Baseline Study of Middle Grade Students in the United States. Journal Of Environmental Education. 41(1), 56-57.

Mujib, M. (2013). Pengaruh Penggunaan Internet Terhadap Hasil Belajar Siswa Sekolah Menengah Atas di Yogyakarta. Skripsi tidak diterbitkan Universitas Sunan Kalijaga Yogayakarta.

Riski, P. (2016). Keadilan Lingkungan yang Makin Mengecewakan Masyarakat. http://www.mongabay.co.id/2016/01/06/keadilan-lingkungan-yang-makin-mengecewakan-masyarakat/ (online) diakses pada 13 November 2016.

Roth, C. E. (1992). Environmental Literacy: Its roots, evolution and directions in the 1990s. Columbus, OH: ERIC/SMEAC Information Reference Center.

Sumarmi. (2008). Sekolah Hijau Sebagai Alternatif Pendidikan Lingkungan Hidup Dengan Menggunakan Pendekatan Kontekstual. Jurnal Ilmu Pendidikan. Jilid 15: 19-25.

Supardi, I. (1994). Lingkungan Hidup dan Kelestariannya. Bandung: Alumni.

Undang-undang No. 32. (2009). Tentang Perlindungan dan Pengelolaan Lingkungan Hidup pasal 65 poin keempat.

Utami, R,P., Probosari, R,M., \& Fatmawati, U. (2015). Pengaruh Model Pembelajaran Project Based Learning Berbantu Instagram Terhadap Kemampuan Berpikir Kreatif Siswa Kelas X SMA Negeri 8 Surakarta. Bio Pedagogi. 4(1). 47-52. 
Jurnal MIPA dan Pembelajarannya, 1(1), 2021, 14-24

Varişli, T. (2009). Evaluating Eighth Grade Students' Environmental Literacy: The Role of Socio-Demographic Variables. Tesis tidak diterbitkan. Middle East Technical University.

Wena, M. (2009). Strategi pembelajaran inovatif kontemporer: suatu tinjauan konseptual operasional. Jakarta: Bumi Aksara. 